\title{
Perceptions of Thai Teachers of English Towards English Medium Instruction: A Case Study of a Local Primary School
}

\author{
Tawanshine Penthisarn ${ }^{1} 8$ (D) $\triangle$ and Pilanut Phusawisot ${ }^{2} \mathbf{8}$ (D) \\ ${ }^{12}$ Postgraduate student, Department of Western Languages and Linguistics, Faculty of Humanities and Social Science, \\ Mahasarakham University, Thailand \\ $\triangle$ Corresponding Author: Tawanshine Penthisarn, E-mail: P.Tawanshine@gmail.com
}

\author{
ARTICLE INFORMATION \\ Received: July 11,2021 \\ Accepted: August 04, 2021 \\ Volume: 3 \\ Issue: 9 \\ DOI: 10.32996/jeltal.2021.3.9.2
}

\section{KEYWORDS}

English medium instruction, Teacher's perceptions, Thai Teacher of English

\section{ABSTRACT}

Using a case study approach, this study investigated teachers' perceptions of EMI, the challenges teachers encountered while adopting EMI, and opportunities for EMI in Thai EFL classrooms. The participants were three Thai teachers who used English as a medium of instruction in subjects such as mathematics and science in an intensive English program at a private primary school in the northeastern part of Thailand. Data were obtained from teachers' journals and semi-structured interviews. The data were transcribed and coded into themes using content analysis. The current study reports the perceptions of Thai EFL teachers and reveals the challenges of EMI in Thai EFL classrooms. As the findings reveal, the participants perceived EMI as an educational advantage, as preparation for the international community and as an approach to enhance students' speaking confidence. Although EMI offers potential benefits, the study reveals that when teaching, the participants are challenged by students' language proficiency, classroom size, a lack of teaching materials, teacher's lack of content knowledge and a lack of support from the school. Moreover, the study suggests some recommendations for pedagogical implication in adopting EMI in Thai EFL classrooms.

\section{Introduction}

English is one of the most widely used and spoken languages globally and has become a medium of communication in every domain globally (Coleman, 2006; Graddol, 2006). As such, English proficiency has become a priority for higher education institutions and has led to the internationalization of universities around the globe. This has led to a drive to adopt English as the medium of instruction (EMI) in non-English speaking countries.

English medium instruction (EMI) has been defined as the use of the English language to teach content subjects other than the English subject itself in countries where English is not the first language (L1) (Macaro et al., 2018) and is becoming more prevalent in contexts where English is commonly treated as a foreign language (Dafouz \& Camacho-Minano, 2016). However, Macaro (2015) described EMI as the most significant educational internationalization trend as it provides students with the double benefits of subject knowledge and English language skills. Many governments and students believe that EMI will make them more attractive in the global employment market (Galloway, 2017). This push towards EMI has become an important issue, especially in Asian countries, where English is used second and foreign languages (Evans, 2002). Therefore, public and private universities and schools in many countries have introduced English as a medium of instruction in the curriculum.

In Thailand, The Office of the Basic Education Commission (OBEC) began to establish English Programs in schools throughout the country in 1995. These schools are known as "E.P. schools" or "bilingual schools" and use English as a medium of instruction. These programs have been increasing very rapidly in recent decades in order to meet globalization demands and improve English proficiency while maintaining a high academic standard.

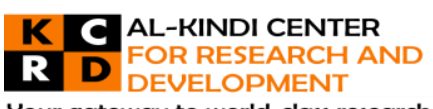

Your gateway to world-class research

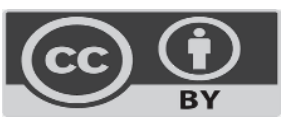

Published by Al-Kindi Center for Research and Development, United Kingdom. Copyright (c) the author(s). This open access article is distributed under a Creative Commons Attribution (CC-BY) 4.0 license 
In summary, the popularity of EMI has increased among primary and secondary schools in Thailand. However, due to the lack of studies at the primary education level on EMI, more studies are needed as EMI has been increasingly adopted. Indeed, it is a commonly held notion that EMI seems to be the best approach to teaching English in a foreign language classroom, but the challenges and needs associated with this teaching method have not been assessed from the perspective of primary school teachers. As such, the current study set out to examine Thai teachers' perceptions of EMI and the challenges that these teachers encounter with EMI use in their classrooms. It is important to conduct this study because as EMI becomes more prevalent in a Thai EFL context, this study can contribute more understanding to the perceptions of Thai primary school teachers regarding the use of EMI, uncover information on the challenges teachers face when teaching in an English medium, and provide suggestions on instructional strategies to best implement EMI in a Thai EFL context.

\section{Literature Review}

\subsection{English medium instruction}

English-medium instruction (EMI) refers to the use of the English language to teach content subjects other than the English subject itself. It is usually offered in university degrees in higher education in countries where English is not the first language to achieve internationalization (Macaro et al., 2018) Fueled by globalization, including the flow of people, capital, knowledge, business, science, and technology, EMI is now a global phenomenon ( $\mathrm{Hu} \& \mathrm{Li}, 2017$ ).

This has created a demand for a world lingua franca to communicate with each other, and English has become the global language (Coleman, 2006; Hu, 2018). Several factors have contributed to the increase of EMI in European countries, East Asian nations, and other national contexts. First, many countries view EMI as a key factor to enrich their countries, especially in science, technology, commerce, and education (Kweon \& Kim, 2017). Moreover, ministries of education view EMI as an effective strategy to raise the quality of higher education and develop twenty-first-century skills in their students (Airey et al., 2017) and stakeholders promote EMI as a means of internationalizing tertiary education to attract international or domestic students (Wilkinson 2013). Indeed, several universities in Europe and Asia have implemented EMI to enhance employability skills and the competitiveness of their graduates in global and domestic markets (Hu et al.,2014).

\subsection{English Education in Thailand}

Currently, formal education in Thailand is divided into two levels, basic and higher education. The present basic education system is a 6: $3: 3$ system, consisting of six years of primary education, three years of lower secondary education, and three years of upper secondary education. Higher education is divided into two levels, which are lower than degree level and degree level. The English language in Thai education is taught from basic education to higher education levels. English is also classified as the first foreign language and is considered a critical subject for students in their studies and future careers. In Thailand, the teacher/student ratio is 1:21 (OEC, 2007). However, in practice, the actual ratio is approximately 1:40. Indeed, in Thai schools, teachers hold several responsibilities, including administration, financial management, activities, and managing supplies. This has caused a teacher shortage and the use of out of field teachers, who teach subjects outside of the field of their own higher education. This is especially true for English teachers as less than $20 \%$ of English teachers in Thailand have degrees in the field of English language.

\subsection{Importance of English in primary education in Thailand}

Primary education is one of the most important foundations and the first stage of education for children to gain a better standard of living and welfare. When children become adults, language education is the key to developing social interactions, self-expression, and personal development that will help them to achieve lasting positive and rewarding results (UNESCO, 2012). In Thailand, children generally enter Grade 1 at the age of 7 and finish Grade 6 at the age of 12. Some children may, in fact, start learning English at an earlier age. However, the age that children start learning English has been increasing around the globe as parents believe that the younger their children learn English, the easier and faster their children will acquire language (Graddol, 2006). In addition, the Thai government recognizes that English proficiency is necessary for Thai children. Today, English language teaching is fundamental for Thailand's basic education system (Foley, 2005). Moreover, the demand for English for young learners (EYL) has been increasing in many Asian contexts as English becomes a tool for communicating, exploring new knowledge, understanding a diversity of culture, producing visions of the world community and solving global issues (Mackenzie, 2008). In 1999, a reform of the English language curriculum in Thailand was introduced in the new curriculum, as English became a compulsory foreign language subject from the first grade (Prapphal, 2008). However, it is important for policymakers, educators and scholars to develop strategic English language teaching policies and practices in order to catch up with the global trend for primary level English language education in other ASEAN nations. 


\section{Methodology}

The current study describes the research design and methodology used in this study. It also presents the procedures for data collection and data analysis. The stages for the instrumentation plan and research procedures are described. Researchers' positionality and ethical consideration are also included.

\subsection{Participants and Setting Participants}

The participants in this study were three Thai teachers who were drawn from a convenience sampling of the researcher's former colleagues. The participants were teachers who taught in the intensive English program with the use of English as a medium of instruction in subjects such as mathematics and science at a private primary school in the northeastern part of Thailand. The information about the participants is described below:

- $\quad$ The first teacher, Skyla, is a female teacher. She has experience in using EMI for four years. Her students are primary 1 and 3. At this level, she claimed that at the beginning using English as a medium of instruction was difficult for primary 1. She had used several techniques in teaching and selecting materials. However, students in primary 3 have better understanding in class and most of the students in this class could communicate.

- The second teacher is Nicholas. He is a male teacher teaching in the intensive program for five years. He teaches students in primary 2, 5 and 6 in both math and science. At this level, students tended to have a high proficiency in English. They could interact with the teacher in class. They could communicate in basic conversations and understood the content of the subjects as the teacher always taught them essential vocabulary and encouraged them to speak in class.

- $\quad$ The third teacher, Jasmine, is a female teacher with five years of experience in using EMI. She finished her master's degree in arts in Thailand. She taught math and science in primary 3 and 4 using English as a medium of instruction. Using this teaching approach, she noticed that at the end of the semester students developed a better command in speaking English.

\section{Setting}

The study was conducted in a private primary school in the northeastern part of Thailand. The school consists of around 1,500 students. However, only 750 students are enrolled in the intensive English program where English is used as a medium of instruction. The students in the Intensive English Program have to pay extra tuition fees. The curriculum of this program allows students to study content subjects such as math and science in English. In this study, there were three Thai teachers who teach in this program in this school.

\subsection{Research Instruments}

\section{Teacher's Journal}

In this study, a teacher's journal was one of the instruments used to examine teacher's perception and challenges that teachers encountered. The data obtained from the teacher's journal was analyzed and used to support the data collected from the semistructured interviews. The teacher's journal was an essential tool to help reflect on how the teacher conducted the class, how they prepared the lessons, what challenges they faced in class, what teachers did in class to improve students' understanding, what teaching techniques they used, what problems they had in class, how they solved the problems, and what problems the teachers were unable to solve in adopting EMI. The participants were asked to write a daily journal about using EMI in their classroom. The researcher designed the form for the journal and asked the teachers to respond to the questions in the journal.

\section{Semi-structured Interviews}

Semi-structured interviews were conducted as an instrument for collecting in-depth qualitative data. Three teachers who used EMI in a primary school were selected for semi-structured interviews. The teachers were asked to provide information about their perceptions of EMI as well as the challenges of EMI in Thai EFL classrooms. The interviews were conducted in Thai in order to put the participants at ease since both the researcher and the participants are all Thai.

\subsection{Data Collection Procedure}

The study was conducted using a case study approach. Teacher's journals and semi-structured interviews were employed in order to investigate the teachers' perceptions and the challenges of teaching in a Thai EFL classroom. The researcher contacted the participants in order to get permission to collect the data from them about using English as a medium of instruction and they were selected by convenience sampling. The participants were asked to write a journal for three classes. Next, the semistructured interviews were also used to answer the questions related to the perception of English as a medium for instruction 
and the challenges of implementing EMI. The interviews were audio-recorded. Immediately after the interview, the recordings were transcribed from Thai to English. The transcriptions were then brought back to the participants for verification. In doing so, the trustworthiness of the interview was established.

\subsection{Data Analysis}

The data collected from the teacher's journals and the recorded interviews were transcribed and coded by using content analysis in order to gain more understanding and perspectives. The data collected from the teacher's journal and the semi-structured interviews were triangulated in order to interrogate different ways of understanding the situation. The transcriptions were coded into themes as the findings of this study. At the final stage, the researcher sent the transcription and theme to the three participants for member checking in order to check the trustworthiness and confirm the reliability of the findings.

\subsection{Researcher's positionality}

According to Savin-Baden \& Major (2013) positionality "reflects the position that the researcher has chosen to adopt within a given research study." Positionality influences how research is conducted. In this study, the researcher has personal experience as a former English teacher who used English as a medium of instruction in an intensive English program and is a former colleague of the participants. Therefore, this position might, may, or have, directly or indirectly influenced the design, execution, and interpretation of the research data findings (Greenbank, 2003; May \& Perry, 2017)

\section{Results and Discussion \\ Research question \#1: What are the teachers' perceptions towards EMI in a Thai EFL classroom? Educational advantage}

The participants in this current study perceived EMI as a beneficial approach for students. They revealed that adopting EMI in a Thai EFL primary classroom improves students' language skills including their speaking and listening skills. Moreover, students have more chances to be exposed to English and are encouraged to speak English. In addition, the participants also think that EMI will provide an opportunity for students in the future and prepare them to study abroad, to be a global citizens, or for indemand careers that need English speakers. The statements below illustrate these opinions:

"I think EMI can be an education advantage for students in many ways including, more opportunities for students to have exposure to English, increasing students' language proficiency, increasing vocabulary knowledge and improving students speaking and listening skills..."

"I think adopting EMI in the Thai EFL classroom is obviously a benefit for students, especially learning English at a young age, as students can learn faster and better. I think students who are in an EMI class will be ready to study abroad and meet the demand for a career that needs an English speaker..."

(Nicholas)

"In my opinion, I consider EMI as a beneficial approach, as there are many advantages such as it being a way to improve students' language proficiency including speaking and listening skills. I also think that EMI will help students to have a good career in the future..."

(Jasmine)

The findings above illustrate that participants perceived EMI as a beneficial approach for student learning as it helps to improve language skills and proficiency, especially listening and speaking skills. In addition, students are exposed to English every day and they have access to various English sources and materials. The teachers also reported that EMI led students to have better opportunities in the future and better career prospects.

\section{Speaking confidence}

The second theme that emerged related to speaking confidence. The participants agreed that EMI improves students' confidence and also offers more exposure to English and more opportunities to practice their English. The participants perceived EMI as a means to improve student English proficiency. The results indicated that EMI enhanced student's confidence in speaking English. In this study the participants revealed that the students in an EMI class have more exposure to English. students are encouraged to speak English. The result also suggested that in an EMI class students tend to speak English confidently, students are willing to participate, and want to answer questions. Besides, EMI helps to boost students' confidence. Students tend to speak more, and their speaking skills are improved. The statement below shows the teachers' perception of student's confidence: 
"They feel more confident about speaking English. They are not afraid to ask questions. They are trying to speak more when they have the chance. I think EMI is very helpful in improving student's language skills as they try to communicate."

(Skyla)

"I think that with the use of English in an EMI class students have exposure to English and have confidence in speaking English, they have more chances to speak and express themselves. Students get to learn new vocabulary every day and I always repeat the lesson and vocabulary. I think students will absorb more by listening and speaking in an EMI class..."

(Nicholas)

"...In my opinion, students who are in an EMI class have confidence in speaking English. It is inevitable to say that EMI has actually motivated students' learning and improved students' confidence in speaking English. From my experience, students will try to ask questions or answer questions in English even when they don't know all the words, but at least they have tried."

(Jasmine)

As shown above, the participants reported that students in an EMI class are more confident in speaking English. Students were willing to engage with the teacher, they enjoyed the class and were motivated to answer questions and speak in English. Moreover, the participants reported that EMI helps to build students' speaking confidence and improve their speaking skills as the students often tried to use English to communicate with the teacher. Overall, the present results indicate that EMI enhances student's confidence in speaking as students have more exposure to English which can be one of the key factors to adopt EMI in a Thai EFL context successfully.

\section{Preparation for international society}

The analysis of the semi-structured interviews also indicated that the participants perceived EMI as a preparation for international society. The participants reported that students who are in an EMI class are prepared for the international community such study abroad or for study at an advanced level. Besides, they also noted that EMI is a tool to prepare students for the twenty-first century and EMI seems to guarantee students' future academic success. The following excerpt revealed the teachers 'perceptions of EMI with regards to how EMI is perceived as a preparation for international society. The participants revealed that:

"...students who are in EMI classes are prepared for an international standard. I think EMI helps students to improve in many ways. For example, when they do the National Test, they can do it well. I think EMI helps students to prepare to be a global citizen..."

"Learning math and science from primary level will help students to prepare themselves for study abroad or study at an advanced level. It will definitely help develop both students' written and spoken skills. In the meantime, students absorb some technical vocabulary or terms in science and math as well."

(Nicholas)

"...it is preparing students to be ready for the 21st century and it seems to guarantee their academic success in the future. Moreover, I think EMI also prepares them to get a demanding career in the global market..."

(Jasmine)

As shown in the interview extracts above, the participants described the long-term benefit of EMI as preparation for the international community. The result of this study revealed that teachers perceived EMI as a preparation for the international community as EMI provides students with educational support for their further study and future career.

\section{Research question \#2: What are challenges teachers encounter in adopting EMI in a Thai EFL classroom? Student language proficiency}

Unsurprisingly, the concern most often expressed is about the students' English language proficiency and the teachers' proficiency, or both. The participants revealed that most students in an EMI class have low English proficiency which led to a challenge in adopting EMI. Moreover, students' English proficiency can be one of the major disadvantages of learning nonEnglish subjects in an EMI classroom. For example, the participants reported that: 
"Most students have low English proficiency. I think students' English proficiency is one of the main reasons that adopting EMI in Thailand is challenging. Textbooks, and teaching materials are in English, and with the teacher also only speaking English most of the time students don't understand the content and what the teacher says..."

"Most students have low English proficiency. EMI can be difficult for students which may cause some problems. For example, students don't want to study because they don't understand, they feel embarrassed when they can't do the task in class, and they have low self-esteem when speaking English..."

(Nicholas)

"Students' English proficiency can be one of the major disadvantages of learning in an EMI classroom. Sometimes, the content is too difficult for students. However, I think using English as a medium to instruct math and science is designed for students who have good to high English proficiency and skills. But for those who have low English proficiency it is challenging for the teacher because they can't communicate, understand, and follow the lesson..."

(Jasmine)

The statements above confirm that students' English proficiency is a significant challenge to both teachers and students. The teachers claimed that EMI is somewhat effective with students who are adequate with English. In this study, the teachers conducted lessons 100 percent in English, and therefore the students who do not have high proficiency suffer from demotivation and struggle. As seen from the excerpt above, both Skyla and Nicholas said, "Most students have low English proficiency." It can therefore be deduced that it is common for teachers to encounter challenges with students' language proficiency and background knowledge and for students to struggle. However, when the teacher provides guidance, students will take the risk to speak and achieve the goals the teacher set.

\section{Large classroom size}

According to the interviews, all participants revealed that the current classroom size is too big (at around 45 students) for effective EMI instruction as it limits classroom activities. The findings also reveal that the size of classrooms was another challenge that teachers encountered. Moreover, the participants also reported that they encounter challenges in creating classroom activities and in controlling the classroom. Thus, large classroom sizes may be ineffective. However, the effect of class size on teaching and learning English as a foreign language (EFL) has been a contentious debate among researchers for a long time. The statement below highlights this part of the teachers' reports:

"Everyone wants to be a part of activities, sometimes, I have to choose volunteers and some students are not happy about it. Sometimes when we are doing activities students scream, shout and play. Due to the classroom size of 45 students, it is very big and it's hard to have control and focus."

"I think the challenge in creating classroom activities is classroom size. We have around 45 students in each class, and it is very difficult to do activities. Some students want to be a part of the game, but due to the size of the classroom we don't have time for everyone to do all the activities. Another challenge is that it is very difficult to control the class and help students. I think a big classroom causes ineffective teaching performance and students are less engaged."

(Nicholas)

"I find it difficult to control. Sometimes students talk and play. Sometimes when students need help, I cannot fully help them because I have to take care of the whole class..."

(Jasmine)

As shown above, the participants agreed that the classroom size is too big for adopting EMI in a Thai EFL context as the teacher needs to facilitate students' learning while also planning strategies, techniques, and activities for the classroom. Moreover, all participants also revealed that they face difficulties in conducting classes which caused problems for their teaching performance. Therefore, large classroom size was a major factor that affected students' responses and distracted students, lowering the efficiency of the class.

\section{Lack of teaching material}


Another theme shared by participants related to teaching materials. The participants stated that EMI requires that they prepare a large number of teaching materials. Moreover, teachers must carefully consider the details of the materials and be creative. The participants reported that the teaching materials for EMI are not on the market and they must create resources themselves. This preparation takes a considerable amount of time which causes dissatisfaction as they must prepare many different materials to teach many subjects and levels. The statement below illustrated the teachers' lack of access to teaching materials:

"Teaching materials for EMI classes are not on the market. I always have a hard time preparing teaching materials because it takes time. I have to prepare a large amount of paper flash cards and pictures. Moreover, for the PowerPoint slides I have to make it easy to understand and interesting. We cannot find these teaching materials anywhere; yet we have to create ones that match the book..."

"I have to teach many levels and three subjects; it is very challenging and miserable for me to prepare teaching materials. I have to prepare pictures, flash cards, PowerPoints, video and sometimes need authentic material to facilitate students' learning and understanding in the lesson. For example, pictures have to be big, PowerPoint has to be interesting for kids, put something that can move, pictures of a famous singer or cartoon etc."

(Nicholas)

"...preparing teaching materials takes a long time and I have to prepare many teaching materials as I teach many subjects and levels. Sometimes, I just don't want to do it because it is time consuming, I have to look for videos, pictures and make an interesting PowerPoint for the students."

(Jasmine)

As detailed in the interview extracts, the participants reported that they teach several education levels, and they have little time to prepare teaching materials. Moreover, some participants also revealed that it is difficult to find authentic material and that preparing interesting teaching materials is too time-consuming. This suggests that a lack of accessible materials heightens the teachers' workload, potentially affecting their teaching performance and motivation.

\section{Teachers' lack of content knowledge}

The participants revealed that they feel insecure and are not confident about their teaching performance. They reported that some subject content is challenging, which caused their teaching performance to be less effective. The following statements support this finding:

"... I think what is challenging for me is subject content. I am not very good at math. When I teach at a higher level, I feel insecure about my knowledge, I don't feel I can explain confidently. I have to read over it many times and ask other teachers. I'm still not sure about my teaching performance..."

"...In some subjects or lessons, I don't quite understand, some of the lessons are very complex. Sometimes, before I teach, I have to ask another teacher that has expertise in the subject matter. However, I still don't feel confident with my teaching."

(Nicholas)

"...I am struggling sometimes for topics in each lesson. I don't think I have enough time to check more details to enhance my understanding. If I don't have adequate knowledge, it's possible that I may have a chance to deliver the wrong lessons, which has happened several times in my teaching career."

(Jasmine)

Overall, the participants revealed that they feel insecure and lack the content knowledge to teach using an EMI approach. They reported that some content is challenging for them, especially when they teach at a higher level. Moreover, they reported that they do not feel confident with their teaching. The excerpts above revealed that teachers in this current study have a lack of content knowledge as they are not specialist subject teachers. They voiced that they struggle when they have to teach the contents of some subject they don't understand and therefore don't feel confident with their teaching.

\section{Lack of support}

The participants shared some of their perceptions that school should provide an environment that facilitates students to learn English. Moreover, the participants also expressed that they need support from stakeholders to work together in order to adopt EMI successfully. The excerpt below shows that teachers think they lack support from their school: 
"...I think the school should provide an environment to learn English for students such as an English corner where they have English books and games. Students can learn English by themselves, and they get exposed to more English..."

"...We need support from stakeholders such as school administrators, policy makers, parents and teachers to work together. Maybe manage an activity for students to be exposed to English. When at home parents need to support and encourage their children to have exposure to English..."

(Nicholas)

"I think school has to provide an English room or English Clinic where students can explore English books and materials, they can play games or can chat with a teacher in English. Another thing is the school should consider reducing class sizes because the classes are too big."

(Jasmine)

The participants explained that the school should provide activities and an environment that supports students' learning. It also showed that teachers think that they lack support from the school as well. Moreover, the findings also noted that teachers think schools should provide an English room in which students can explore English books and materials and have activities to enrich the students' language proficiency. In summary, this finding indicated that teachers in an EMI class lack support from school authorities. They expressed that they want students to get exposure to English outside of the classroom to develop language competence.

\section{Conclusion}

In recent years, the popularity of EMI has increased among primary and secondary schools in Thailand, due to the lack of studies at the primary education level on EMI, more studies are needed as EMI has been increasingly adopted. As such, the current study was set out to investigated teacher's perceptions and to identify the challenges encountered by the teachers in primary education as result of the use of English as the medium of instruction in an EFL context. The study has revealed the teacher's perceptions and the teacher's challenges in adopting EMI in Thai primary school. The study illustrated two main aspects regarding EMI in Thai EFL classrooms as followed: teachers' perceptions and teachers' challenges.

The finding showed that the participants perceived EMI as an educational advantage and EMI was seen as a beneficial approach, including improving students' language proficiency and improving students' vocabulary knowledge. Moreover, the participants also perceived EMI as an approach to enhance student' confidence in speaking. The participants explained that students was given more exposure to English sources and they had more chances to speak English in an EMI classroom. The other perception shared by the participants was a preparation for the international society. They noted that EMI internationalized Thai education and helped prepare student in a better way for an international career (Tatzl, 2011).

However, the current study also focused on investigated the challenges teachers encountered when adopting EMI in a Thai EFL classroom. The participants revealed five main challenges that teacher encountered including student's language proficiency, classroom size, teacher's lack of content knowledge, lack of teaching materials and lack of support from the school. One of the major challenges in adopting EMI was student's language proficiency. The participants explained that students in EMI class had low English proficiency which caused a challenge to both teacher and students. Moreover, the participant's voice that classroom size was another challenge they encountered which limited activities in classroom and led to ineffective teaching performance of teacher and student's learning. Moreover, the participants also revealed that they lacked content knowledge. The participants in this study were English teachers who used English to teach content subjects. They expressed that they felt insecure when they were not confident about the content. This led to the poor teaching performance. Moreover, teaching material was another challenge; they stated that they had to develop teaching material and it was time-consuming which caused them miserable workload. Another challenge was teachers' lack of support from school. The participants voice that they need support from school to listen to their challenges and developed strategies that helped them to adopt EMI successfully.

In conclusion, the current study sheds lights on various aspects, raises significant issues, and yields useful information regarding the instructional strategies in implementing EMI in Thai EFL context. The findings suggest that school should provide activities associated with English learning to promote student's motivation in learning English and language development. Moreover, they also suggested that reducing class size can have an impact on students learning, as the teacher can focus on their teaching approach and skills. To reduce the size of a classroom, school authorities should evaluate the benefits and downsides of classroom reduction and seek solutions of the problem together. In addition, teaching materials are also found to be challenging for EMI teachers. The participants suggest that teachers need to select appropriated materials for the lesson and adopt games

Page | 20 
and other useful activities in classroom to increase interactions and build a positive reinforcement. Another recommendation shared by the participants is lack of teacher content knowledge development. The suggestion to develop this challenge is a collaborative between EMI teachers and content teachers who have expertise in that subject matter. Moreover, teacher should also prepare a lesson beforehand in order to deliver the correct content and can come up with strategies and approaches to help students learn in an EMI class.

\subsection{Limitations of the Study}

There is a limitation found in this study. Since this study employed a convenience sampling method as a way to select the participants, how the researcher interprets the data could be subjective. To make the findings more trustworthy, it is suggested that suture research use a purposive sampling as this method keeps a balance of how the researchers interprets the data.

\subsection{Recommendation for Further Studies}

This study used convenience sampling as the way to select the participants. The participants in this study were the former colleagues of the researcher. Therefore, it is suggested that future study should be conducted using a purposive sampling. Moreover, researcher positionality also affects how the participants interpret information. It may affect the validity and trustworthiness of the data. Hence, it is suggested that the further study use a co-researcher and a triangulation of researcher in order to minimize researcher bias and improve trustworthiness of findings.

Funding: This research received no external funding

Acknowledgements: I would like to express my deep sense of gratitude to my advisor, Dr. Pilanut Phusawisot, for her extraordinary cooperation, invaluable guidance, and supervision.

Conflicts of Interest: The author declares no conflict of interest.

\section{References}

[1] Airey, J., Lauridsen, K. M., Räsänen, A., Salö, L., \& Schwach, V. (2017). The expansion of English-medium instruction in the Nordic countries: Can top-down university language policies encourage bottom-up disciplinary literacy goals. Higher education, 73(4), 561-576.

[2] Coleman, J. A. (2006). English-medium teaching in European higher education. Language teaching, 39(1), 1-14.

[3] Dafouz, E., \& Camacho-Miñano, M. M. (2016). Exploring the impact of English-medium instruction on university student academic achievement: The case of accounting. English for Specific Purposes, 44, 57-67.

[4] Evans, S. (2002). The medium of instruction in Hong Kong: Policy and practice in the new English and Chinese streams. Research Papers in Education, 17(1), 97-120.

[5] Foley, J. A. (2005). English in... Thailand. RELC Journal: A Journal of Language Teaching and Research, 36(2), 223-234.

[6] Galloway, N. (2017). Global Englishes and change in English language teaching: Attitudes and impact. Taylor \& Francis.

[7] Graddol, D. (2006). English next (Vol. 62). British council.

[8] Greenbank, P. (2003). The role of values in educational research: The case for reflexivity. British educational research journal, 29(6), 791-801.

[9] Hu, G., \& Li, X. (2017). Asking and answering questions in English-medium instruction classrooms: What is the cognitive and syntactic complexity level?. In English-medium instruction in Chinese universities: Perspectives, discourse and evaluation(pp. 184-203). Taylor and Francis.

[10] Kammasorn, N., \& Prapphal, K. (2008). The web-based C-test as a placement test for learners of English with a focus on test-takers' strategies. Unpublished Ms.

[11] Kim, E. G., Kweon, S. O., \& Kim, J. (2017). Korean engineering students' perceptions of English-medium instruction (EMI) and L1 use in EMI classes. Journal of Multilingual and Multicultural Development, 38(2), 130-145.

[12] Macaro, E. (2015). English medium instruction: Time to start asking some difficult questions. Modern English Teacher, $24(2), 4-7$.

[13] Macaro, E., Curle, S., Pun, J., An, J., \& Dearden, J. (2018). A systematic review of English medium instruction in higher education. Language Teaching, 51(1), 36-76.

[14] Mackenzie, A. S. (2008, March). English next in easy Asia. In The proceeding of primary innovations regional seminar (pp. 23-30).

[15] May, Tim and Beth Perry. (2017). Reflexivity: The Essential Guide. Sage.

[16] Savin-Baden, M., \& Howell-Major, C. (2013). Qualitative Research: The Essential Guide to Theory and Practice. Routledge.

[17] Birmingham, P., \& Wilkinson, D. (2003). Using research instruments: A guide for researchers. Routledge.

[18] Hu, G., Li, L., \& Lei, J. (2014). English-medium instruction at a Chinese University: Rhetoric and reality. Language Policy, 13(1), 21-40. 